\title{
Comparison between the different new anti-coagulants for non-valvular atrial fibrillation: network meta-analysis
}

\author{
Hala Mohammed Albutti*
}

Department of Pharmacy, King Fahad Armed Forces Hospital, Jeddah, Saudi Arabia

Received: 10 December 2018

Accepted: 05 January 2019

\section{*Correspondence to:}

Dr. Hala Mohammed Albutti, Email: halaalbuti@outlook.com

Copyright: (C) the author(s), publisher and licensee Medip Academy. This is an openaccess article distributed under the terms of the Creative Commons Attribution NonCommercial License, which permits unrestricted noncommercial use, distribution, and reproduction in any medium, provided the original work is properly cited.

\begin{abstract}
Background: Atrial fibrillation is associated with high risk of ischaemic stroke which is considered a major fatal complication in atrial fibrillation. That's why, anticoagulants were used to prevent this major complication. However, anticoagulants themselves are associated with their own complications. A systematic search of Embase, Medline and Google scholar were conducted. The included papers were extracted for outcomes related to the complications of each drugs. A Bayesian network meta-analysis based on Markov chain Monte Carlo simulation (MCMC) with 10000 burn-in iterations and 50000 inference iterations. We found eighteen papers that fit our inclusion criteria. Apixaban had the least risk of major bleeding compared to Warfarin [HR $=0.536,95 \%(0.448$, 0.652)] and the least risk of gastrointestinal hemorrhage. For stroke risk, the Rivaroxaban had the least risk compared to Warfarin $[\mathrm{HR}=1.05,95 \%(0.98$, 1.14)]. For intracranial hemorrhage, dabigatran had the least risk of intracranial haemorrhage compared to Warfarin $[\mathrm{HR}=0.46,95 \% \mathrm{CrI}(0.36,0.61)]$. For the thromboembolism risk, other non-vitamin $\mathrm{k}$ antagonist had the least risk of intracranial haemorrhage compared to Warfarin $[\mathrm{HR}=0.523,95 \%(0.095,2.85)]$. There were no conclusive results about the best anticoagulant drugs for nonvalvular atrial fibrillation. Apixaban was the least among them to be associated with major bleeding, while rivaroxaban was ranked the first with least stroke complications. Furthermore, dabigatran was associated with less risk of intracranial haemorrhage compared to other anticoagulants.
\end{abstract}

Keywords: Anti-coagulant, Atrial fibrillation, Drugs, Non-valvular heart disease

\section{INTRODUCTION}

Atrial fibrillation is most common prevalent cardiac arrythmia representing 2.3 million in United States increasing up to 5.6 to 7.56 million by 2050 . The higher the age, the higher the incidence of atrial fibrillation reaching up to 18 in 100 patients of 85 aged patients. ${ }^{1}$ The atrial fibrillation represents a major public health problem with significant morbidity and mortality. It is a disturbance of electrical activity in the atrial that cause rapid contraction of the ventricles which may be paroxysmal or persistent. ${ }^{1}$ The most dangerous complication of atrial fibrillation is systemic embolism. The management of the atrial fibrillation includes anti-arrhythmic and anticoagulants. ${ }^{1}$ The anti-coagulants are used to decrease risk of systemic embolism; it was estimated that in 2003, about $46-53 \%$ of patients with atrial fibrillation were receiving a vitamin $\mathrm{K}$ antagonist. Still, many complications are reported for anticoagulants. ${ }^{1-3}$ Major bleeding, fatal bleeding and intracranial haemorrhage are among many complications reported for vitamin $\mathrm{k}$ anti-coagulants. ${ }^{1}$ Major bleeding was reported in 20 of 1000 atrial fibrillation patients of which 0.5 to 1 percent has fatal bleeding. Intracranial haemorrhage occurred in about $0.2 \%$ of the patients. ${ }^{1,4}$ Other bleeding from gastrointestinal tract was reported from warfarin use., ${ }^{2,5}$ Warfarin is characterized by narrow therapeutic window and slow 
onset. ${ }^{2,5}$ This urged the use of the new generation of anticoagulants. The most investigated new anti-coagulants are apixaban, dabigatran and rivaroxaban. Rivaroxaban and apixaban are factor Xa inhibitors while dabigatran is direct thrombin inhibitors. ${ }^{3,6}$ Comparative studies showed apixaban reduced the risk of stroke without increasing the risk of bleeding while rivaroxaban had the same efficacy of the warfarin..$^{7-12}$ However, there are heterogenous results of the efficacy of the new oral anti-coagulants compared to vitamin $\mathrm{k}$ antagonist. Studies reported that the switching of the patients from warfarin to dabigatran had increased the risk of major bleeding. ${ }^{13,14}$ Larsen et al, found that there are higher numbers of the myocardial infarction and major bleeding in patients switched to Warfarin. ${ }^{9}$ Dabigatran was found to be associated with wide safety margin while rivaroxaban was found to have better and more potent effect than both dabigatran and apixaban. ${ }^{15,16}$ However, there is still contradictory results about the best fit for treatment of atrial fibrillation.

In this network meta-analysis, we are going to compare between rivaroxaban, dabigatran and apixaban regarding its complications.

\section{METHODS}

\section{Search strategy}

A systematic search was conducted from the January 2010 on EMBASE, Medline and Google Scholar. Search terms used are (apixaban OR apixaban OR rivaroxaban OR rivaroxaban OR "dabigatran etexilate" OR "dabigatran etexilate" OR "novel anticoagulants" OR "new anticoagulants" OR "novel anticoagulant" OR "new anticoagulant" OR "newer anticoagulants" OR "newer anticoagulant" OR "new oral anticoagulant") AND (("Atrial Fibrillation" OR "Atrial Fibrillation" OR "Atrial Flutter" OR "Atrial Flutter") OR (nonvalvular OR nonvalvular OR nonvalvar)) OR (NVAF OR "nonvalvular atrial fibrillation" OR “non-valvular AF”).

Manual search was conducted by checking relevant papers on PubMed and papers which cited the included studies. We also checked the systematic review and meta-analysis for any relevant studies.

\section{Eligibility criteria}

Eligibility criteria were studies that specify that patients had non-valvular atrial fibrillation as other types were associated with other risk factors that bias our analysis, and therefore, specifically exclude patients with valvular conditions (e.g., mitral valvular disorders). Treatments of interest included apixaban, rivaroxaban, edoxaban, or dabigatran of any dose or duration compared to each other or compared to vitamin $\mathrm{k}$ antagonist. We only included full-text articles, and only studies reporting relative effect estimates (hazard ratios [HRs], odds ratios [ORs], risk ratios [RRs]) for complications. Observational studies (e.g., prospective and retrospective cohort studies, case-control studies, database/registry studies) were eligible for inclusion. We only included real-world observational studies. RCTs, systematic reviews or meta-analyses, narrative reviews, single-arm studies, case reports, case series and crosssectional studies were excluded from the analysis.

\section{Data extraction}

The standardized template was developed through a pilot extraction with the two most relevant references. The data were extracted into the template. Extracted data included: authors, publication year, baseline characteristics of participants including sample size, age of patients, gender and educational. Risk statistics for each complication were extracted.

\section{Quality assessment of included studies}

Authors independently assessed the quality and risk of bias in included studies using the NIH quality assessment tool. It is a 14 questions tool that assess the quality of observational studies, each question had "yes" or "no" answers. ${ }^{17}$

\section{Statistical method}

Bayesian contrast based random effect model network based on Markov chain Monte Carlo simulation (MCMC) was employed to indirectly compare different methods of administration using Control as a common comparator and rank the best approach as the best one to produce significant decrease in the anxiety score. The statistical analysis is based on binomial likelihoods with a standardized mean difference (SMD) function. Vague priors were assigned so it was less likely to affect the model results; GeMTC package automatically determines the uniform prior distribution heuristically setting a value for the outcome scale parameter.

We used four chain each with 10000 burn-in iterations and 50000 inference iterations; convergence was assessed via inspecting the Brooks-Gelman-Rubin graphs and the Potential Scale Reduction Factor by which we considered our iterations are enough when it is below 1.05. We also checked the accuracy of our Markov simulation was assessed by density plots and Monte Carlo error. The model fit was assessed using the deviance information criterion (DIC). ${ }^{18}$ The heterogeneity in random effect model was assessed by inspecting the heterogeneity in individual studies. The inconsistency of the model was assessed using node splitting model. ${ }^{18}$

The ranking of treatments was performed in each chain of MCMC by counting the proportions of iterations that each type of therapy is the first, the second and so on. Our model results are presented using SMD and 95\% credible interval. GeMTC package was used in $\mathrm{R} 3.3 .0$ for performing the analyses. 


\section{RESULTS}

\section{Search results}

We had 5562 papers relative to our research terms; only 18 papers were eligible for network meta-analysis. The flow of the search is illustrated in Figure 1.

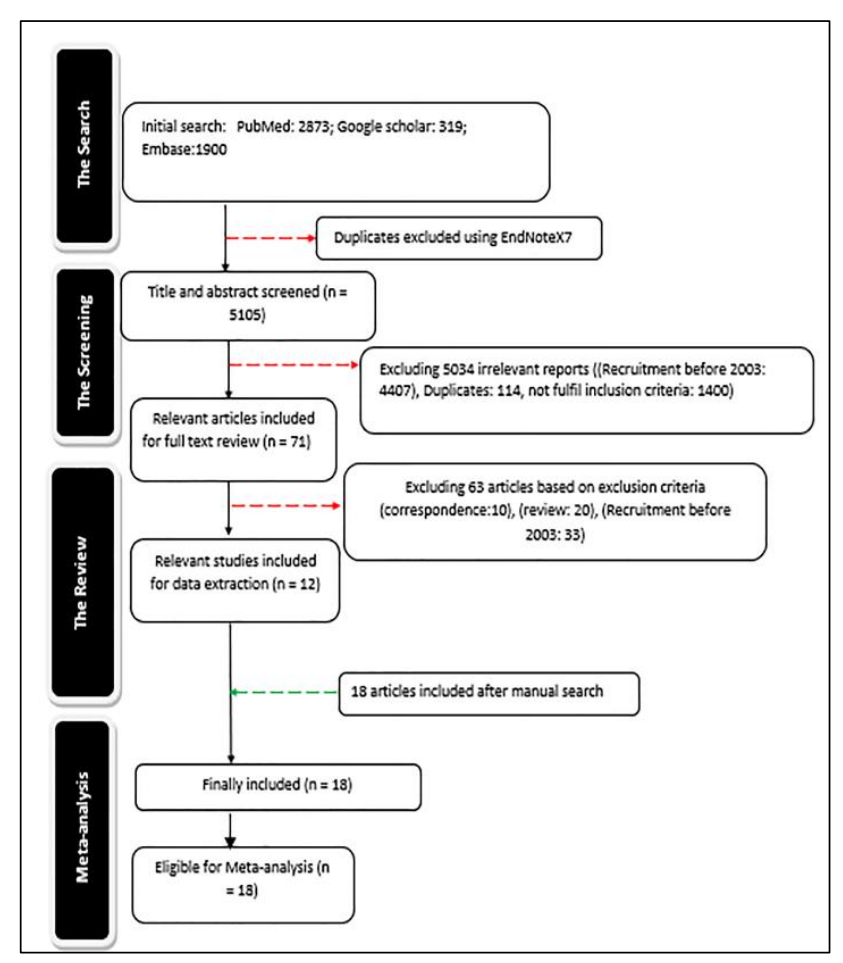

Figure 1: The method for the search, abstract screening, systematic review and meta-analysis.

\section{Study characteristics}

We included 18 studies, the study and patients' characteristics are illustrated in Table 1.

\section{Quality assessment}

Based on NIH bias tool, twelve studies have a good quality while the rest had a fair quality. Most studies lacked blinding and absence of reference assessment common to all studies. The explanation of assessment of the quality are explained in Supplementary Table 1.

\section{Comparison between different new oral anti-coagulants regarding the major bleeding risk}

The network included five arms representing warafarin, Dabigatran, Rivaroxaban, non-vitamin $\mathrm{k}$ antagonist and apixaban Figure 2A. Based on the ranking probability Figure $2 \mathrm{C}$, the apixaban had the least risk of bleeding compared to Warfarin $[\mathrm{HR}=0.536,95 \%(0.448,0.652)]$ followed by Dabigatran $[\mathrm{HR}=0.726,95 \%$ CI $(0.641$, 0.859)] Figure 2B.
Unexpectedly, the warfarin surpassed the Rivaroxaban and other non-vitamin $\mathrm{K}$ antagonist Figure 2C. The comparison between different new oral anti-coagulants is presented in Table 2 .

The network was consistent as evident by the $\mathrm{P}$-value = 0.78 ; there was no heterogeneity as the standard deviation of the random effect model is less than the effect size and within the pairwise comparisons. The model is considered fit as present in Supplementary Table 2.

\section{Comparison between different new oral anti-coagulants regarding the risk of stroke}

The network included four arms representing warafarin, Dabigatran, Rivaroxaban, and apixaban Figure 3A. Based on the ranking probability Figure $3 \mathrm{C}$, the rivaroxaban had the least risk of stroke compared to warfarin [HR $=1.05$, $95 \%(0.98,1.14)]$ followed by dabigatran $[\mathrm{HR}=1.03,95 \%$ CrI $(0.91,1.04)]$ Figure 3B. Unexpectedly, the apixaban had the highest risk for the stroke $[\mathrm{HR}=1.07,95 \% \mathrm{CrI}$ $(0.91,1.26)]$. The comparison between different new oral anti-coagulants is presented in Table 3 . The network was consistent as evident by the P-value $=0.8$; there was no heterogeneity as the standard deviation of the random effect model is less than the effect size (Table 2).

\section{Comparison between different new oral anti-coagulants regarding the risk of intracranial haemorrhage}

The network included four arms representing warafarin, Dabigatran, Rivaroxaban, and apixaban Figure 4A. Based on the ranking probability Figure $4 \mathrm{C}$, Dabigatran had the least risk of intracranial haemorrhage compared to Warfarin $[\mathrm{HR}=0.46,95 \% \mathrm{CrI}(0.36,0.61)]$ followed by Apixaban $[\mathrm{HR}=0.64,95 \% \mathrm{CrI}(0.36,1.13)]$ followed by Rivaroxaban Figure 4B. The comparison between different new oral anti-coagulants is presented in Table 4. The network was consistent as evident by the $\mathrm{P}$-value $=$ 0.63. The model is considered fit as present in Supplementary Table 2 .

\section{Comparison between different new oral anti-coagulants regarding the risk of gastrointestinal hemorrhage}

The network included four arms representing warafarin, Dabigatran, Rivaroxaban, and apixaban Figure 5A. Based on the ranking probability Figure 5C, Apixaban had the least risk of gastrointestinal haemorrhage compared to Warfarin $[\mathrm{HR}=0.756,95 \%(0.438,1.28)]$ Figure 5B. The other two anti-coagulant had more risk than warfarin to develop gastrointestinal bleeding. The comparison between different new oral anti-coagulants is presented in Table 5. The network was consistent as evident by the Pvalue $=0.58$; there was no heterogeneity as the standard deviation of the random effect model is less than the effect size. The model is considered fit as present in Supplementary Table 2 . 
Table 1: The characteristics table of the included studies.

\begin{tabular}{|c|c|c|c|c|c|}
\hline Author, year & $\begin{array}{l}\text { Study Design/ Source of } \\
\text { data }\end{array}$ & Region & Enrolled Period & Follow-Up & $\begin{array}{l}\text { Quality } \\
\text { judgement }\end{array}$ \\
\hline Abraham et al ${ }^{10}$ & retrospective cohort & USA & $\begin{array}{l}\text { November } 2010 \text { to } \\
\text { September } 2013\end{array}$ & NA & $\begin{array}{l}\text { Good } \\
\text { quality }\end{array}$ \\
\hline Avgil-Tsadok et al ${ }^{19}$ & retrospective cohort & Canada & $1999-2013$ & 14 years & $\begin{array}{l}\text { Good } \\
\text { quality }\end{array}$ \\
\hline Bouillon et $\mathrm{al}^{20}$ & retrospective cohort & France & $\begin{array}{l}\text { January } 2011 \text { to } \\
\text { November } 2012\end{array}$ & 8 months & Fair quality \\
\hline Chan et $\mathrm{al}^{21}$ & retrospective cohort & Taiwan & $\begin{array}{l}\text { February } 2013 \text { to } \\
\text { December } 2013\end{array}$ & $1 \mathrm{y}$ & $\begin{array}{l}\text { Good } \\
\text { quality }\end{array}$ \\
\hline Colemn et $\mathrm{al}^{22}$ & retrospective cohort & Germany & $\begin{array}{l}\text { January } 2012 \text { to } \\
\text { October } 2013\end{array}$ & 6 months & $\begin{array}{l}\text { Good } \\
\text { quality }\end{array}$ \\
\hline Graham et al $^{8}$ & Prospective cohort & USA & $\begin{array}{l}\text { October } 2010 \text { and } \\
\text { December } 2012\end{array}$ & $\begin{array}{l}2 \text { years and } 2 \\
\text { months }\end{array}$ & Fair quality \\
\hline $\begin{array}{l}\text { Gorst-Rasmussen et } \\
\mathrm{al}^{23}\end{array}$ & Registry & Denmark & $\begin{array}{l}\text { February } 2012 \text { to July } \\
2014\end{array}$ & $\begin{array}{l}2 \text { years and } \\
\text { five months }\end{array}$ & Fair quality \\
\hline Halvorsen et $\mathrm{al}^{7}$ & Registry & Norway & $\begin{array}{l}\text { January } 2013 \text { to June } \\
2015\end{array}$ & six months & Fair quality \\
\hline Hernandez et $\mathrm{al}^{24}$ & retrospective cohort & USA & $\begin{array}{l}\text { October 1, 2010, } \\
\text { through October } 31 \text {, } \\
2011 \text {, }\end{array}$ & One year & Fair quality \\
\hline Lalibert et $\mathrm{al}^{25}$ & retrospective cohort & USA & May 2011 to July 2012 & $\begin{array}{l}1 \text { year and two } \\
\text { months }\end{array}$ & Fair quality \\
\hline Larsen et al ${ }^{9}$ & retrospective cohort & Denmark & $\begin{array}{l}\text { August } 2011 \text { to } \\
\text { October } 2015\end{array}$ & $\begin{array}{l}4 \text { years and } \\
\text { two months }\end{array}$ & $\begin{array}{l}\text { Good } \\
\text { quality }\end{array}$ \\
\hline Lauffenburger et $\mathrm{al}^{26}$ & $\begin{array}{l}\text { large US database of } \\
\text { commercial and } \\
\text { Medicare supplement } \\
\text { claims }\end{array}$ & USA & $\begin{array}{l}\text { October } 2010 \text { to } \\
\text { December } 2012\end{array}$ & Two years & Fair quality \\
\hline Lip et al $^{15}$ & retrospective cohort & USA & $\begin{array}{l}\text { January } 2012 \text { to } \\
\text { December } 2014\end{array}$ & six months & $\begin{array}{l}\text { Good } \\
\text { quality }\end{array}$ \\
\hline Maura et $\mathrm{al}^{2}$ & retrospective cohort & France & July to November 2012 & five months & Fair quality \\
\hline Noseworthy et al ${ }^{12}$ & $\begin{array}{l}\text { data from Optum Labs } \\
\text { Data Warehouse } \\
\text { (OLDW) }\end{array}$ & USA & $\begin{array}{l}\text { October 1st, } 2010 \text { and } \\
\text { February 28th, } 2015\end{array}$ & five years & Fair quality \\
\hline Seeger et $\mathrm{al}^{13}$ & $\begin{array}{l}\text { two commercial health } \\
\text { insurance databases } \\
\text { (MarketScan, Truven and } \\
\text { Clinformatics, Optum) }\end{array}$ & USA & October 2010 to Decembe & er 2012 & $\begin{array}{l}\text { Good } \\
\text { quality }\end{array}$ \\
\hline Staerk et a ${ }^{14}$ & Registry & Denmark & 2011-2015 & 4 years & Fair quality \\
\hline Villines et al ${ }^{11}$ & $\begin{array}{l}\text { US Department of } \\
\text { Defense Database }\end{array}$ & USA & $\begin{array}{l}\text { October } 2009 \text { to July } \\
2013\end{array}$ & $\begin{array}{l}3 \text { years and } \\
\text { five months }\end{array}$ & Fair quality \\
\hline Yao et $\mathrm{al}^{27}$ & retrospective cohort & USA & $\begin{array}{l}\text { October } 2010 \text { to June } \\
2015\end{array}$ & $\begin{array}{l}4 \text { years and six } \\
\text { months }\end{array}$ & $\begin{array}{l}\text { Good } \\
\text { quality }\end{array}$ \\
\hline
\end{tabular}

\section{Comparison between different new oral anti-coagulants regarding the risk of thromboembolism}

The network included four arms representing warafarin, Dabigatran, Rivaroxaban, and non-vitamin k antagonist Figure 6A.

Based on the ranking probability Figure 6C, non-vitamin $\mathrm{k}$ antagonist had the least risk of intracranial haemorrhage compared to Warfarin $[\mathrm{HR}=0.523,95 \%(0.095,2.85)]$ followed by Dabigatran $[\mathrm{HR}=0.0 .54,95 \% \mathrm{CrI}(0.11$, 2.52)] followed by Rivaroxaban $[\mathrm{HR}=1.823,95 \%(0.37$, 9.28)] Figure 6B.

The comparison between different new oral anticoagulants is presented in Table 6. The network was consistent as evident by the P-value $=0.9$; there was no heterogeneity as the standard deviation of the random effect model is less than the effect size. The model is considered fit as present in Supplementary Table 7. 
Table 2: Comparison of the included interventions for the risk of major bleeding: hazard ratio (95\% $\mathrm{CrI})$.

\begin{tabular}{|lllll|}
\hline Intervention column 1 & Intervention column 2 & Intervention column 3 & Intervention column 4 & Intervention column 5 \\
\hline Rivaroxaban & $0.995(0.875,1.113)$ & $0.533(0.444,0.648)$ & $0.722(0.653,0.824)$ & $0.889(0.641,1.254)$ \\
\hline & Warfarin & $0.536(0.448,0.652)$ & $0.726(0.641,0.859)$ & $0.896(0.639,1.278)$ \\
\hline & & Apixaban & $1.357(1.124,1.662)$ & $1.668(1.155,2.428)$ \\
\hline & & Dabigatran & $1.229(0.887,1.693)$ \\
\hline
\end{tabular}

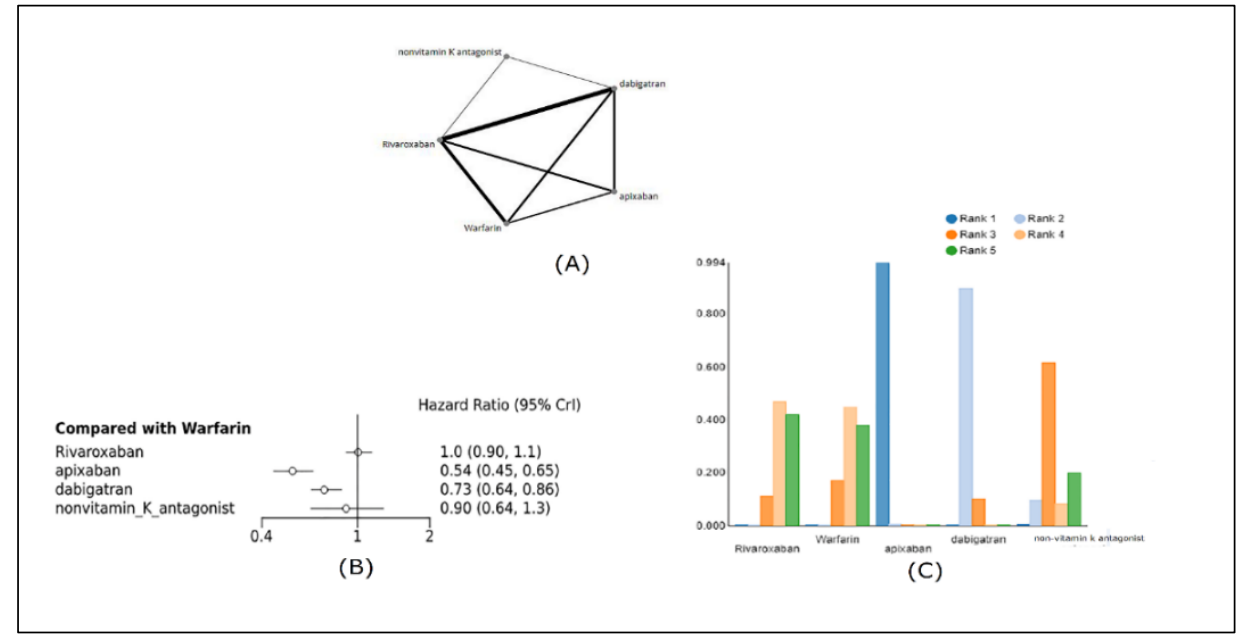

Figure 2: Network of treatments included in the network meta-analysis of risk for bleeding, A) The network graph, B) The random effect model forest plot showing the risk of bleeding for each type compared to warfarin, and C) The ranking probability for the risk of bleeding of different types of anticoagulants.

Table 3: Comparison of the included interventions for the risk of stroke: hazard ratio (95\% CrI).

\begin{tabular}{|llll|}
\hline Intervention column 1 & Intervention column 2 & Intervention column 3 & Intervention column 4 \\
\hline Rivaroxaban & $1.058(0.983,1.144)$ & $1.134(0.951,1.346)$ & $1.025(0.944,1.116)$ \\
\hline & Warfarin & $1.070(0.906,1.263)$ & $0.969(0.905,1.036)$ \\
\hline & & Apixaban & $0.905(0.765,1.076)$ \\
\hline & & Dabigatran \\
\hline
\end{tabular}

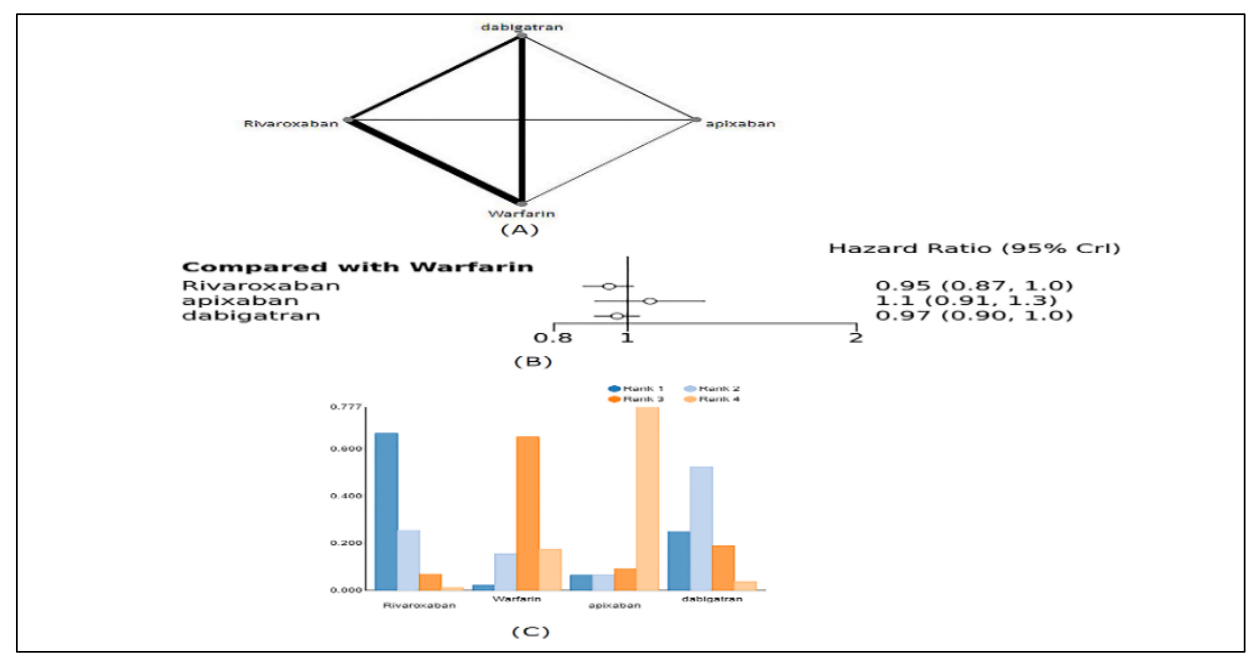

Figure 3: Network of treatments included in the network meta-analysis of risk for stroke, A) The network graph, B) The random effect model forest plot showing the risk of stroke for each type compared to warfarin, and C) The ranking probability for the risk of stroke of different types of anticoagulants. 
Table 4: Comparison of included interventions for the risk of intracranial hemorrhage: hazard ratio (95\% CrI).

\begin{tabular}{|c|c|c|c|}
\hline Intervention column 1 & Intervention column 2 & Intervention column 3 & Intervention column 4 \\
\hline \multirow{3}{*}{ Rivaroxaban } & $1.299(0.769,2.230)$ & $0.828(0.431,1.626)$ & $0.607(0.352,1.053)$ \\
\hline & Warfarin & $0.635(0.363,1.133)$ & $0.467(0.357,0.609)$ \\
\hline & & Apixaban & $0.734(0.405,1.301)$ \\
\hline
\end{tabular}

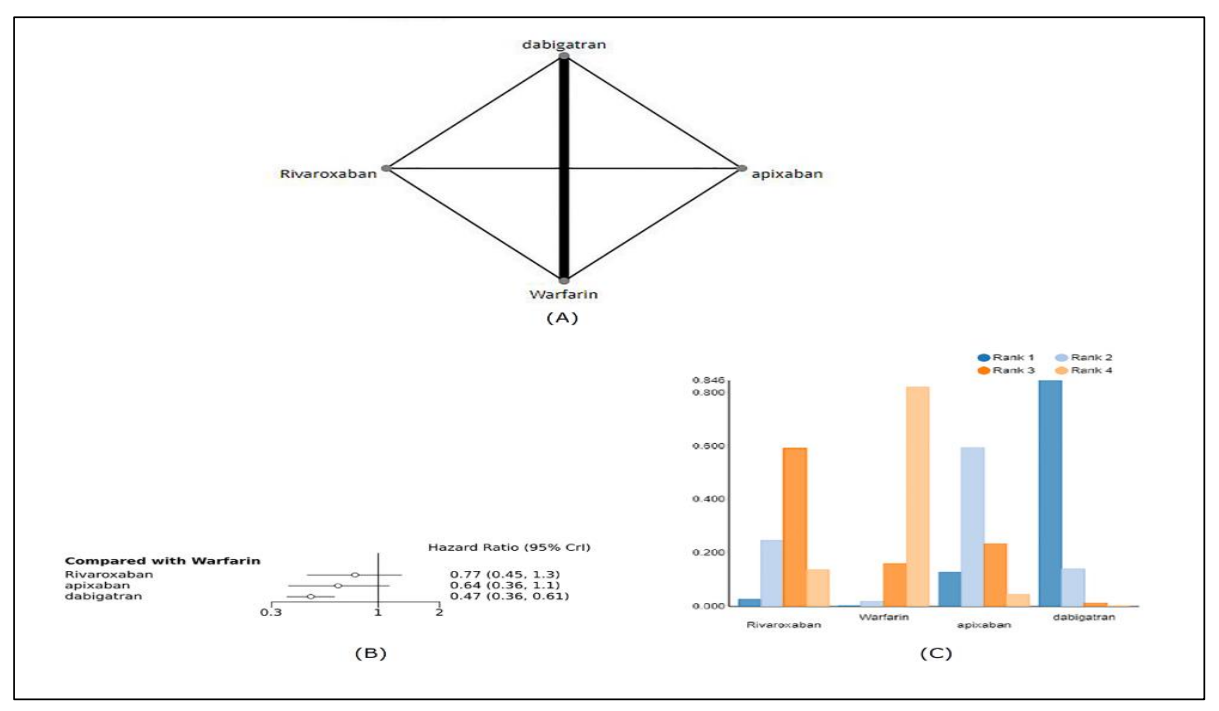

Figure 4: Network of treatments included in the network meta-analysis of risk for intracranial hemorrhage, A) Network graph, B) The random effect model forest plot of risk of intracranial hemorrhage for each type compared to warfarin, C) Ranking probability for the risk of intracranial hemorrhage of different types of anticoagulants.

Table 5: Comparison of included interventions for risk of gastrointestinal hemorrhage: hazard ratio (95\% $\mathrm{CrI})$.

\begin{tabular}{|llll|}
\hline Intervention column 1 & Intervention column 2 & Intervention column 3 & Intervention column 4 \\
\hline Rivaroxaban & $0.748(0.453,1.258)$ & $0.567(0.307,1.046)$ & $0.894(0.538,1.512)$ \\
\hline & Warfarin & $0.756(0.438,1.280)$ & $1.195(0.986,1.424)$ \\
\hline & Apixaban & $1.579(0.921,2.725)$ \\
\hline
\end{tabular}

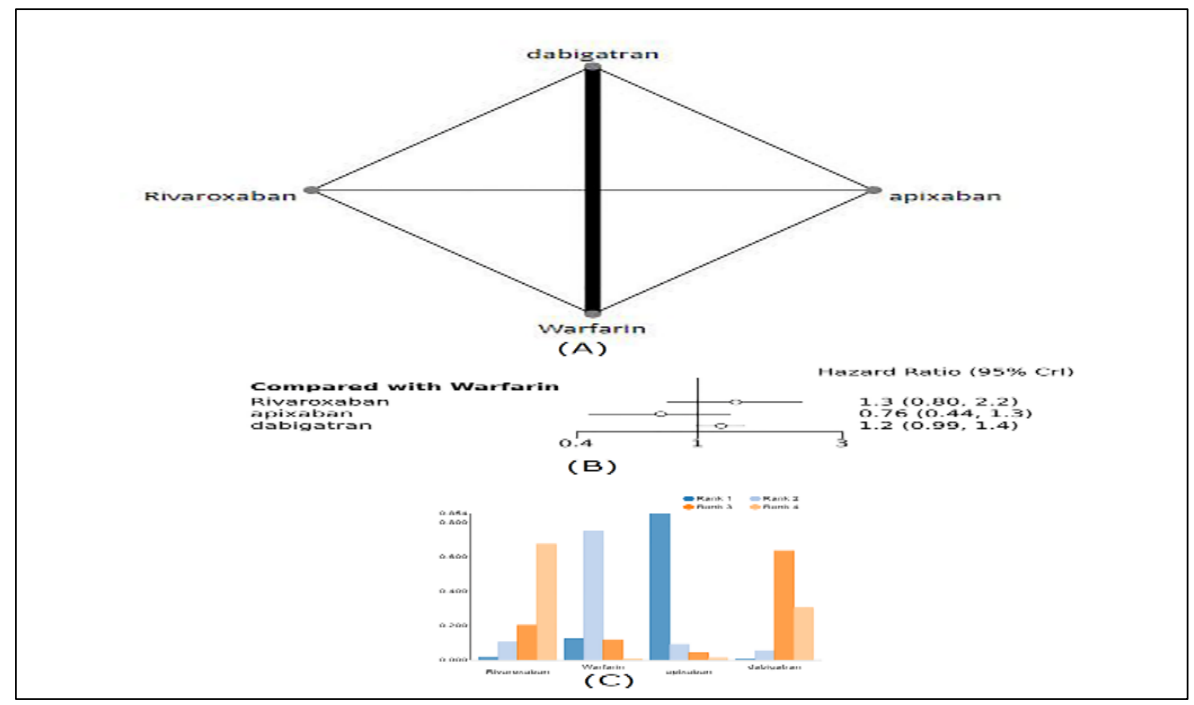

Figure 5: Network of treatments included in the network meta-analysis of risk for gastrointestinal haemorrhage, $\mathrm{A}$ ) Network graph, B) Random effect model forest plot of risk of gastrointestinal haemorrhage for each type compared to warfarin, and C) Ranking probability for the risk of gastrointestinal haemorrhage of different anticoagulants. 
Table 6: Comparison of the included interventions for the risk of thromboembolism: hazard ratio (95\% $\mathrm{CrI})$.

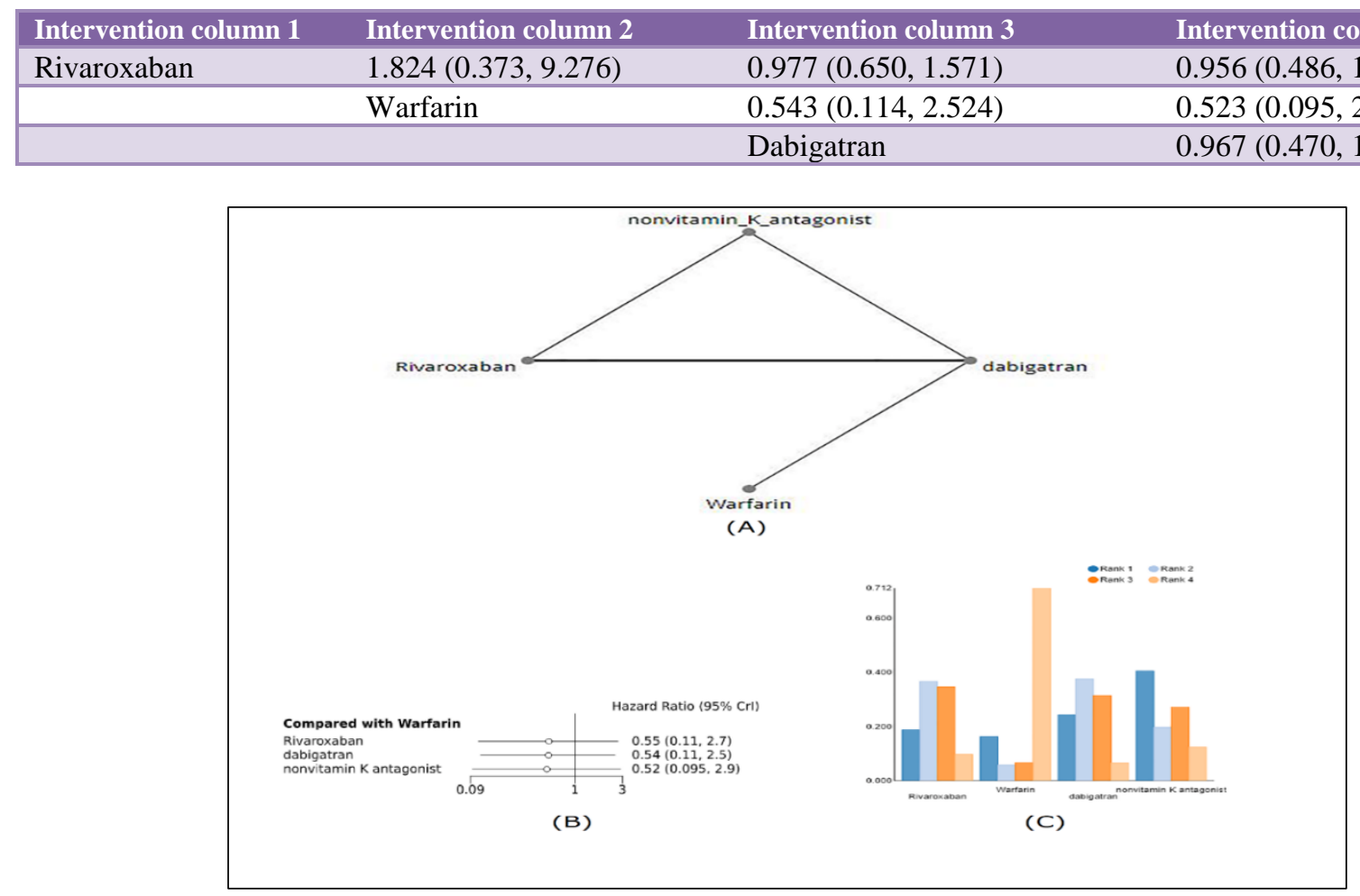

Figure 6: Network of treatments included in the network meta-analysis of risk for thromboembolism, A) Network graph, B) Random effect model forest plot showing the risk of thromboembolism for each type compared to warfarin, and C) Ranking probability for the risk of thromboembolism of different types of anticoagulants.

\section{DISCUSSION}

This study is set out to compare between the best anticoagulant treatment for non-valvular atrial fibrillation with the least complication. Despite the inconclusive results, we found that. Apixaban had the least risk of major bleeding compared to Warfarin $[\mathrm{HR}=0.536,95 \%(0.448,0.652)]$ and the least risk of gastrointestinal hemorrhage. For stroke risk, the Rivaroxaban had the least risk compared to Warfarin $[\mathrm{HR}=1.05,95 \%(0.98,1.14)]$. For intracranial hemorrhage, Dabigatran had the least risk of intracranial haemorrhage compared to Warfarin $[\mathrm{HR}=0.46,95 \% \mathrm{CrI}$ $(0.36,0.61)]$. For the thromboembolism risk, other nonvitamin $\mathrm{k}$ antagonist had the least risk of intracranial haemorrhage compared to Warfarin $[\mathrm{HR}=0.523,95 \%$ $(0.095,2.85)]$.

Stroke is a major complication of atrial fibrillation; usual anti-coagulants are used to prevent this complication. ${ }^{1,2}$ However, with the high side effects of the vitamin $\mathrm{K}$ antagonist, search for new anti-coagulants with less side effects was initiated. ${ }^{5}$ This group included apixaban, Rivaroxaban and Dabigatran which are used for nowadays as alternative for usual anti-coagulants. Still, with contradicting results, the choice of the best one of them is not easy due to the risk of complications for each one. ${ }^{13,28,29}$

Regarding major bleeding, our results were consistent with previous meta-analyses that apixaban was the best approach with less risk of major bleeding. ${ }^{30}$ A multicentre, multinational, double-blind, randomized trial that compared apixaban with warfarin found that apixaban had less risk of bleeding compared to warfarin. ${ }^{7,12,16}$ Dabigatran was compared to warfarin and was found to has no difference to it regarding the major bleeding but was significantly associated with decreased rate intracranial haemorrhage. ${ }^{19,30}$ This supports our results as Dabigatran was the least among them to have intracranial haemorrhage. For major bleeding, the dabigatran was the second after apixaban to be less associated with risk of major bleeding which contradict these studies as it was superior to warfarin. The same was found for rivaroxaban, two randomized clinical trial found that rivaroxaban was equivalent to warfarin regarding the risk for bleeding and better regarding the risk of stroke, embolism and intracranial haemorrhage. ${ }^{8,31}$ Our results support these trials as rivaroxaban had more risk than warfarin for major bleeding and gastrointestinal bleeding. Rivaroxaban's risk of thromboembolism and bleeding was more than other new anticoagulant drugs. Apixaban was considered in other studies is superior to other new oral anticoagulants. ${ }^{32}$ 
A study found that apixaban was associated with survival benefit compared to warfarin. Comparison between apixaban and rivaroxaban found that the apixaban had less risk of bleeding than rivaroxaban. ${ }^{32}$ Dabigitran was found to be superior than rivaroxaban regarding the risk of bleeding and intracranial haemorrhage. ${ }^{12}$ This is like our results which supports the concept that rivaroxaban is less than other new anticoagulants. That study also found that rivaroxaban was also associated with more risk of stroke and ischaemic stroke than dabigatran. ${ }^{12}$

Table 7: Model fit statistics of bleeding risk.

\begin{tabular}{|ll|}
\hline Residual deviance ( $\mathbf{D}_{\text {res }}$ ) & 25.5 \\
\hline Leverage $\left(\mathrm{p}_{\mathrm{D}}\right)$ & 9.9 \\
\hline DIC & 35.4 \\
\hline Number of data points & 19 \\
\hline Model fit statistics of stroke risk & 14.5 \\
\hline Residual deviance (Dres) & 4.9 \\
\hline Leverage (pD) & 19.4 \\
\hline DIC & 21 \\
\hline Number of data points & 14.8 \\
\hline $\begin{array}{l}\text { Model fit statistics of intracranial haemorrhage (ICH) } \\
\text { risk }\end{array}$ & 10 \\
\hline Residual deviance (Dres) & 24.9 \\
\hline Leverage (pD) & 13 \\
\hline DIC & 11.1 \\
\hline Number of data points & 10.1 \\
\hline Model fit Statistics of gastrointestinal bleeding risk \\
\hline Residual deviance (Dres) & 21.2 \\
\hline Leverage (pD) & 11 \\
\hline DIC & 4.7 \\
\hline Number of data points & 4.2 \\
\hline Model fit statistics of thromboembolism risk \\
\hline Residual deviance (Dres) & 9 \\
\hline Leverage (pD) & 5 \\
\hline DIC & \\
\hline Number of data points & \\
\hline
\end{tabular}

Lip et al, found that there was no significant difference between the three new oral anti-coagulants to each other even with different doses. ${ }^{15,16}$ Another study suggested that the apibaxan is the best and most superior to all other anticoagulants. ${ }^{29}$ Another study found that there was no difference in the efficacy between the three new oral anticoagulants. In addition, they found that dabigatran was associated with less risk of stroke and bleeding. ${ }^{33}$ This was also proved by another study which was also found that the three drugs had the same efficacy, but rivaroxaban had the highest risk of bleeding. ${ }^{12}$ Another study found that patients switching to non-vitamin $\mathrm{k}$ antagonist had less risk of bleeding. It was only present in thromboembolism outcome in our study and was considered the least ones associated with the thromboembolic complications. ${ }^{20}$ Another study with Asian patients found that the rivaroxaban and dabigatran were associated with less risk of bleeding, stroke and intracranial haemorrhage. ${ }^{21}$
Nationwide cohort study in atrial fibrillation patients apixaban and dabigatran were associated with a lower risk of major bleeding and higher risk of gastrointestinal bleeding compared with warfarin. ${ }^{7}$

We recommend head to head clinical trials to stand on the best treatment for atrial fibrillation with no significant risk of bleeding and other side effects.

Our results are more reliable than trials or studies that reviewed and analysed clinical trials as the population in clinical trial usually of younger age and limited to specific included populations. In addition, observational and cohort studies usually represent real life patients.

\section{CONCLUSION}

Apixaban was the least among them to be associated with major bleeding, while rivaroxaban was ranked the first with least stroke complications. Furthermore, dabigatran was associated with less risk of intracranial haemorrhage compared to other anticoagulants.

\section{ACKNOWLEDGEMENTS}

Authors would like to thank the Department of Pharmacy in King Fahad Armed Forces Hospital for their support as well as the research committee in providing me with the necessary access and tools to accomplish and complete this research.

\section{Funding: No funding sources \\ Conflict of interest: None declared \\ Ethical approval: Not required}

\section{REFERENCES}

1. Lafuente-Lafuente C, Mahé I, Extramiana F. Management of atrial fibrillation. Bmj. 2009 Dec 23;339:b5216.

2. Maan A, Padmanabhan R, Shaikh AY, Mansour M, Ruskin JN, Heist EK. Newer anticoagulants in cardiovascular disease: a systematic review of the literature. Cardiol Review. 2012 Sep 1;20(5):209-21.

3. Wanat MA. Novel oral anticoagulants: a review of new agents. Postgraduate Med. 2013 Jul 1;125(4):10314.

4. Heeringa J, van der Kuip DAM, Hofman A, et al. Prevalence, incidence and lifetime risk of atrial fibrillation: the Rotterdam study. Euro Heart J. 2006;27(8):949-53.

5. Mekaj YH, Mekaj AY, Duci SB, Miftari EI. New oral anticoagulants: their advantages and disadvantages compared with vitamin $\mathrm{K}$ antagonists in the prevention and treatment of patients with thromboembolic events. Therapeutics Clinical Risk Manag. 2015;11:967.

6. Stangier J, Rathgen K, Stähle H, Gansser D, Roth W. The pharmacokinetics, pharmacodynamics and tolerability of dabigatran etexilate, a new oral direct 
thrombin inhibitor, in healthy male subjects. British J Clin Pharmacol. 2007;64(3):292-303.

7. Halvorsen S, Ghanima W, Fride Tvete I, Hoxmark C, Falck P, Solli O, Jonasson C. A nationwide registry study to compare bleeding rates in patients with atrial fibrillation being prescribed oral anticoagulants. Euro Heart J Cardiovas Pharma. 2016 Sep 27;3(1):28-36.

8. Graham DJ, Reichman ME, Wernecke M, Zhang R, Southworth MR, Levenson M, et al. Cardiovascular, bleeding, and mortality risks in elderly medicare patients treated with dabigatran or warfarin for nonvalvular atrial fibrillation. 2014:157-64.

9. Larsen TB, Skjøth F, Nielsen PB, Kjældgaard JN, Lip GY. Comparative effectiveness and safety of nonvitamin $\mathrm{K}$ antagonist oral anticoagulants and warfarin in patients with atrial fibrillation: propensity weighted nationwide cohort study. BMJ. 2016;353:i3189.

10. Abraham NS, Singh S, Alexander GC, Heien H, Haas LR, Crown W, et al. Comparative risk of gastrointestinal bleeding with dabigatran, rivaroxaban, and warfarin: population based cohort study. BMJ. 2015 Apr 24;350:h1857.

11. Villines TC, Schnee J, Fraeman K, Siu K, Reynolds MW, Collins J, et al. A comparison of the safety and effectiveness of dabigatran and warfarin in nonvalvular atrial fibrillation patients in a large healthcare system. Thrombosis Haemostasis. 2015 Dec;114(06):1290-8.

12. Noseworthy PA, Yao X, Abraham NS, Sangaralingham LR, McBane RD, Shah ND. Direct comparison of dabigatran, rivaroxaban, and apixaban for effectiveness and safety in nonvalvular atrial fibrillation. Chest. 2016;150(6):1302-12.

13. Seeger JD, Bykov K, Bartels DB, Huybrechts K, Zint K, Schneeweiss S. Safety and effectiveness of dabigatran and warfarin in routine care of patients with atrial fibrillation. Thrombosis haemostasis. 2015;55:1277-89.

14. Staerk L, Fosbøl EL, Lip GY, Lamberts M, Bonde AN, Torp-Pedersen C, et al. Ischaemic and haemorrhagic stroke associated with non-vitamin $\mathrm{K}$ antagonist oral anticoagulants and warfarin use in patients with atrial fibrillation: a nationwide cohort study. Euro Heart J. 2016 Oct 14;38(12):907-15.

15. Lip GY, Keshishian A, Kamble S, Pan X, Mardekian J, Horblyuk R, Hamilton M. Real-world comparison of major bleeding risk among non-valvular atrial fibrillation patients initiated on apixaban, dabigatran, rivaroxaban, or warfarin. Thrombosis Haemostasis. 2016 May;115(05):975-86.

16. Lip GYH, Larsen TB, Skjøth F, Rasmussen LH. Indirect comparisons of new oral anticoagulant drugs for efficacy and safety when used for stroke prevention in atrial fibrillation. $\mathrm{J}$ American Coll Cardiol. 2012;60(8):738-46.

17. National Heart, Lung, and Blood Institute (NHLBI). Study Quality Assessment Tools, 2018. Available at: https://www.nhlbi.nih.gov/health-topics/studyquality-assessment-tools.
18. Dias S, Welton NJ, Caldwell DM, Ades AE. Checking consistency in mixed treatment comparison metaanalysis. Statistics Med. 2010;29(7-8):932-44.

19. Avgil-Tsadok M, Jackevicius C, Essebag V, Eisenberg MJ, Rahme E, Behlouli $\mathrm{H}$, et al. Dabigatran use in elderly patients with atrial fibrillation. Thrombosis Haemostasis. 2016;115(01):152-60.

20. Bouillon K, Bertrand M, Maura G, Blotière P-o, Ricordeau P, Zureik M. Risk of bleeding and arterial thromboembolism in patients with non-valvular atrial fi brillation either maintained on a vitamin $\mathrm{K}$ antagonist or switched to a non-vitamin K-antagonist oral anticoagulant: a retrospective, matched-cohort study. The Lancet Haematology. 2015;2(4):e150-9.

21. Chan YH, Kuo CT, Yeh YH, Chang SH, Wu LS, Lee HF, Tu HT, See LC. Thromboembolic, bleeding, and mortality risks of rivaroxaban and dabigatran in Asians with nonvalvular atrial fibrillation. J Am Coll Cardiol. 2016 Sep 27;68(13):1389-401.

22. Coleman CI, Antz M, Bowrin K, Evers T, Simard EP, Bonnemeier $\mathrm{H}$, et al. Real-world evidence of stroke prevention in patients with nonvalvular atrial fibrillation in the United States: the REVISIT-US study. Curr Med Res Opinion. 2016 Dec 1;32(12):2047-53.

23. Gorst-Rasmussen A, Lip GY, Bjerregaard Larsen T. Rivaroxaban versus warfarin and dabigatran in atrial fibrillation: comparative effectiveness and safety in Danish routine care. Pharmacoepidemiology Drug Safety. 2016;25(11):1236-1244.

24. Hernandez I, Baik SH, Pinera A, Zhang Y. Risk of bleeding with dabigatran in atrial fibrillation. JAMA internal medicine. 2015;175(1):18-24.

25. Laliberté F, Cloutier M, Nelson WW, Coleman CI, Pilon D, Olson WH, et al. Real-world comparative effectiveness and safety of rivaroxaban and warfarin in nonvalvular atrial fibrillation patients. Curr Med Res Opinion. 2014 Jul 1;30(7):1317-25.

26. Lauffenburger JC, Farley JF, Gehi AK, Rhoney DH, Brookhart MA, Fang G. Effectiveness and safety of dabigatran and warfarin in real-world US patients with non-valvular atrial fibrillation: a retrospective cohort study. J Am Heart Association. 2015;4(4).

27. Yao X, Abraham NS, Sangaralingham LR, Bellolio MF, McBane RD, Shah ND, et al. Effectiveness and safety of dabigatran, rivaroxaban, and apixaban versus warfarin in nonvalvular atrial fibrillation. J Am Heart Association. 2016 Jun 1;5(6):e003725.

28. Rubboli A, Becattini C, Verheugt FW. Incidence, clinical impact and risk of bleeding during oral anticoagulation therapy. World J Cardiol. 2011;3(11):351-8.

29. Sterne JA, Bodalia PN, Bryden PA, Davies PA, López-López JA, Okoli GN, et al. Oral anticoagulants for primary prevention, treatment and secondary prevention of venous thromboembolic disease, and for prevention of stroke in atrial fibrillation: systematic review, network meta-analysis and cost-effectiveness analysis. Health Technol Assessment Volume. 2017;21(9). 
30. Connolly SJ, Ezekowitz MD, Yusuf S, Eikelboom J, Oldgren J, Parekh A, et al. Dabigatran versus warfarin in patients with atrial fibrillation. New England J Med. 2009 Sep 17;361(12):1139-51.

31. Patel MR, Mahaffey KW, Garg J, Pan G, Singer DE, Hacke W, et al. Rivaroxaban versus warfarin in nonvalvular atrial fibrillation. New Eng J Med. 2011 Sep 8;365(10):883-91.

32. Mantha S, Ansell J. An indirect comparison of dabigatran, rivaroxaban and apixaban for atrial fibrillation. Thrombosis Haemostasis. 2012;108(09):476-84.
33. Rasmussen LH, Larsen TB, Graungaard T, Skjøth F, Lip GY. Primary and secondary prevention with new oral anticoagulant drugs for stroke prevention in atrial fibrillation: indirect comparison analysis. BMJ. 2012 Nov 5;345:e7097.

Cite this article as: Albutti HM. Comparison between the different new anti-coagulants for nonvalvular atrial fibrillation: network meta-analysis. Int J Basic Clin Pharmacol 2019;8:362-71. 